\title{
Desarquivando a ditadura
}

$A$ COletÂneA de artigos intitulada $D e$ sarquivando a ditadura: memória e justiça no Brasil, organizada pela socióloga Cecília MacDowell Santos, pelo professor de Filosofia Edson Teles e pela historiadora Janaína de Almeida Teles, publicada em dois volumes, vem contribuir de maneira substancial com os estudos em torno da ditadura militar e das questões que envolvem a construção da memória sobre os anos de repressão. Trata-se, pois, de uma tarefa conjunta de historiadores, cientistas sociais, filósofos, críticos literários, jornalistas e profissionais do direito na tentativa de esquadrinhar a constituição da memória política e dos diferentes aspectos da justiça relacionados às violações de direitos humanos cometidas durante a ditadura militar no Brasil (p.15). A partir de uma abordagem multidisciplinar, a coletânea de trabalhos visa ao estudo da constituição da memória política por meio de diferentes aspectos teóricos e metodológicos, possibilitando inúmeras abordagens sobre a justiça e as violações de direitos humanos durante o regime militar.

$\mathrm{Na}$ distribuição das colaborações que totalizam 27 capítulos, os autores adotaram alguns recortes temporais didaticamente dispostos com intuito de orientar o leitor nas questões que gradativamente se colocam em torno do tema geral da obra. Desse modo, o primeiro volume da coletânea contém trabalhos que vão do golpe de 1964 até o final de década de 1970. No segundo volume, abrangese, em linhas gerais, o período da redemocratização da sociedade brasileira até a atualidade. Ou seja, no primeiro vo- lume, contemplam-se os capítulos que discutem as práticas sociais, ideologias e instituições do Estado durante a ditadura militar, enquanto o segundo centra-se nas mesmas questões, contudo no contexto de abertura democrática com a anistia política, a partir de 1979.

O primeiro volume composto por quatorze capítulos traz, na sua primeira parte, quatro conjuntos temáticos definidos pela similitude de seus objetos. O primeiro e segundo capítulos procuram considerar a questão dos itinerários político-intelectuais, sobretudo a partir de casos que ganharam dimensão pública pelos meios de comunicação. Assim, o historiador Murilo Leal Pereira Neto reconstrói as trajetórias de Sidney Fix Marques dos Santos, Olavo Hansen e Paulo Roberto Pinto, o Jeremias, no artigo "Sidney, Olavo e Jeremias", perfazendo as biografias desses três militantes trotskistas do Partido Operário Revolucionário: Jeremias foi assassinado por latifundiários em Pernambuco, em 1963, enquanto Sidney e Olavo foram mortos logo após o golpe de 1964.

Dentro da mesma temática, o historiador Mário Sérgio de Moraes, em artigo intitulado "Memória e cidadania: as mortes de Vladimir Herzog, Manuel Fiel Filho e José Ferreira de Almeida", discorre sobre a repercussão desses casos (em especial, a morte de Vlado) nos meios de comunicação e a revelação da operação Jacarta, organizada oficiosamente pelos órgãos de repressão militar que, antes de prender Herzog, já havia capturado outro jornalista, Sérgio Gomes da Silva. Em suma, o autor questio- 
na por que apenas a morte do jornalista suscitou um grande movimento de massas (p.58). Foi esse fato, segundo Moraes, que possibilitou o surgimento de uma discussão específica sobre cidadania no Brasil em plena ditadura militar, abrindo as portas para a consolidação dos direitos políticos e civis (p.61).

No segundo conjunto temático dessa primeira parte, "A liberdade nasce da luta: o nascimento da Organização Socialista Internacionalista na crise da ditadura", de autoria do historiador Everaldo de Oliveira Andrade, e "Servir ao povo de todo coração: mulheres militantes e mulheres operárias no ABC na década de 1970", do também historiador Antonio Luigi Negro, são capítulos que se concentram na discussão em torno da mobilização de trabalhadores pela resistência à ditadura militar. No primeiro caso, Andrade contribuiu para uma reflexão sobre a atuação e a resistência das classes trabalhadoras à ditadura, resgatando a formação e as primeiras resoluções da Organização Socialista Internacionalista, surgida em 1976 (p.723); enquanto o capítulo de Luigi Negro, a partir de uma discussão sobre gênero, aborda a inserção de militantes de esquerda nas fábricas em São Paulo e as relações com as operárias. O autor destaca a relevância da atuação das mulheres nas iniciativas das esquerdas em integrarem seus militantes na produção. $\mathrm{O}$ autor sublinha a importância da relação entre as militantes e as operárias (p.88-9). Ressalta, ainda, a aliança entre empresários e a polícia em reação contrária ao associativismo operário (p.85).

Outro conjunto temático que predominará não apenas no primeiro, como no segundo volume da coletânea é a questão do Judiciário e suas relações com a repressão política operada pelo governo militar. Nesse primeiro volume, destacam-se quatro contribuições: os capítulos "Sistema judiciais e repressão política no Brasil, Chile e Argentina", de autoria do cientista político Anthony W. Pereira; "O sistema penal de exceção em face do direito internacional dos direitos humanos", da professora de Direito Kathia Martin-Chenut; "Violência política e justiça sem fronteiras", da historiadora Samantha Viz Quadrat; e "As Comissões Parlamentares de Inquérito na Câmara dos Deputados durante a crise políticoinstitucional brasileira (1963-1968)", do historiador Silvio Luiz Gonçalves Pereira.

O primeiro trabalho compara a prática dos tribunais militares no Brasil, Chile e Argentina e explicita suas diferenças de atuação na repressão dos opositores e dissidentes políticos (p.204-14). O autor, a partir dessas comparações, postula que sistemas jurídicos conservadores, como o brasileiro, podem evitar alguns excessos das forças de segurança, mas são muito mais problemáticos uma vez terminado o período de governo autoritário (p.218). O capítulo de autoria de Martin-Chenut, a partir de uma perspectiva técnico-jurídica, demonstra de que forma a comunidade internacional, preocupada com a "epidemia" de Estados de exceção (p.225) no mundo, passou a controlar a instauração e o desenrolar desses mecanismos de suspensão da ordem jurídica em tempos de crise, impondo-lhes limites e condenando os desvios na utilização desses mecanismos de urgência (p.242).

O capítulo intitulado "A arte de manter em segredo atos praticados por agentes públicos”, de autoria do jornalista Maurício Maia, com uma aborda- 


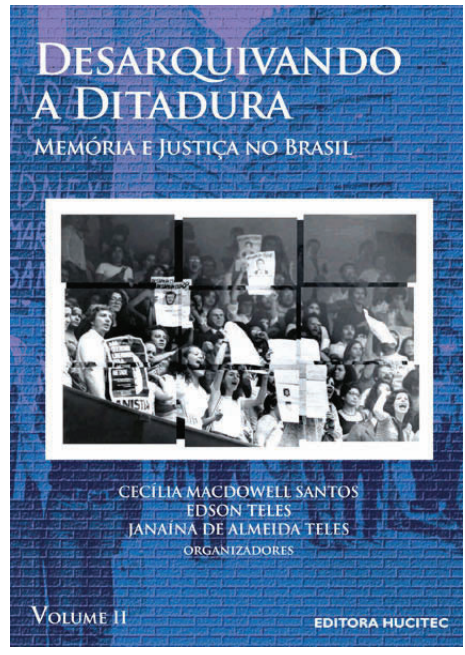

SANTOS, C. M. et al. (Org.) Desarquivando a ditadura: memória e justiça no Brasil. São Paulo: Hucitec, 2009. 597p., 2v.

gem enfática, toma como objeto o que ele denomina "cultura do segredo", no âmbito da administração da justiça criminal. Aborda as relações entre a imprensa, os órgãos de segurança pública e o Tribunal do Júri na cidade de S. Paulo, entre 1960 e 1975 (p.293). Segundo ele, as "zonas sombrias" (p.287) que encobrem o esclarecimento cabal de casos de "desaparecimento" de perseguidos políticos parecem ser o mais grave sintoma da convivência da sociedade brasileira com o sigilo de informações por tempo indeterminado (p.307-8).

A partir dessa mesma perspectiva de análise, outros dois capítulos tangenciam esse conjunto temático. "Violência política e justiça sem fronteiras", de autoria da historiadora Samantha Viz Quadrat, considera a Operação Condor e o impacto das denúncias nos meios judiciais, discutindo de que maneira esses acontecimentos repercutiram no Brasil. Com processos judiciais tramitando em tribunais de vários países, as denúncias da Operação Condor tornaram-se peça fundamental para o fim da impunidade dos crimes de violações dos direitos humanos cometidos pelas ditaduras (p.25762).

Outra colaboração, "As Comissões Parlamentares de Inquérito na Câmara dos Deputados durante a crise políticoinstitucional brasileira (1963-1968)", de Silvio Luiz Gonçalves Pereira, procura relacionar as atividades das Comissões Parlamentares de Inquérito (CPI) da Câmara dos Deputados e a crise político-institucional iniciada após a renúncia de Jânio Quadros, em agosto de 1961 (p.275).

O quarto conjunto temático tem como referencial metodológico a história oral. Tatiana Moreira Campos Paiva, em "Memórias de uma herança: a experiência de filhos de exilados brasileiros da ditadura militar", discute a experiência de exílio de crianças brasileiras, durante a ditadura militar, com base em depoimentos recolhidos (p.136). Esse exílio é identificado pela autora como uma herança caracterizada pela impossibilidade de participação política no processo desencadeado pelas escolhas dos pais, militantes envolvidos com a luta política (p.149). Já o capítulo de Janaína de Almeida Teles, intitulado "Entre o luto e a melancolia: a luta dos familiares de mortos e desaparecidos políticos no Brasil", por meio de instrumental de pesquisa de história oral, recolhe depoimentos de familiares de mortos e desaparecidos políticos. Argumenta que a lembrança do passado, conjugada com o esquecimento das suas fraturas e ausências, registra uma "continuidade aparente" e enfatiza também a sua "perda pela memória" (p.156-9). 
Completando esse primeiro volume, outras três colaborações compõem temas à parte e individualmente abordam objetos mais específicos, mas não menos importantes nessa coletânea. Flamarion Maués analisa a relevância histórica e o processo de produção, edição e distribuição do livro Tortura: a história da repressão politica no Brasil, do jornalista Antonio Carlos Fon, publicado em julho de 1979 (p.110), no artigo intitulado "A tortura denunciada sem meias palavras: um livro expõe o aparelho repressivo da ditadura". Segundo o autor, esse foi o primeiro trabalho jornalístico, publicado pela grande imprensa no Brasil, a demonstrar que o aparato repressivo da ditadura havia sido uma estrutura pensada e desenvolvida de modo sistemático e organizado de acordo com a Doutrina de Segurança Nacional (p.115-9). Em "Tortura e ideologia: os militares brasileiros e a doutrina de guerre révolutionnaire", o cientista político João Roberto Martins Filho discute a influência das ideias francesas da guerre répolutionnaire sobre o exército brasileiro nos anos 1960 e 1970 (p.182-6). Sublinha que durante muito tempo o estudo do pensamento militar se concentrou na chamada DSN, elaborada pela Escola Superior de Guerra, a partir do final dos anos 1940, sob forte influência norte-americana. Martins Filho retoma sua história e argumenta que essa doutrina francesa forneceu uma base ideológica para a ofensiva das Forças Armadas contra o "inimigo interno", com uso sistemático da tortura, e constituiu inspiração para a construção do aparelho repressivo (p.189).

Por fim, o capítulo intitulado "O passado recente em disputa: memória, historiografia e as censuras da ditadura militar", de Douglas Attila Marcelino, coloca em questão a construção da memória que permeia os estudos sobre a censura exercida durante a vigência da ditadura militar no Brasil, procurando ressaltar a atuação do Serviço de Censura de Diversões Públicas (SCDP). Analisa, por exemplo, a conformação de uma memória que somente privilegia a dimensão política da censura então praticada, chamando a atenção para a importância que teve o plano da defesa da moral e dos bons costumes (p.314). O pesquisador explicita a demanda de determinadas parcelas da população brasileira em favor da censura de costumes e a existência de duas censuras bastante distintas no âmbito das publicações de livros e revistas durante a década de 1970 (p.317-22).

O segundo volume contém treze capítulos e, assim como o primeiro, baliza-se em torno de algumas indagações centrais como "qual o papel hoje desempenhado pela memória dos anos de ditadura e pela justiça?” (p.342). A análise suscitada pelos autores é que a transição política do regime militar ao Estado democrático foi feita com base num consenso que negou o caráter público à memória dos horrores da ditadura. Mais que isso: essa memória foi reduzida ao âmbito privado, à memória de indivíduos ou grupos identitários, não incluídos na negociação do pacto político que estabeleceu os parâmetros da redemocratização (p.342-3).

Três grandes blocos temáticos compõem o segundo volume dessa coletânea: anistia, arquivos e memória. Em "O processo político da anistia e os espaços de autonomia militar", do cientista político Samuel Alves Soares e da advogada Larissa Brisola Brito Prado, toma como objeto de análise o processo de anistia durante a redemocratização, pós-1985. 
Os autores demonstram que "a postura militar aderiu ao estatuto da nova legalidade, mas manteve a preservação de 'enclaves de autonomia', decorrentes, entre outros fatores, de uma 'transição pelo alto"” (p.345). Isso porque a Lei de Anistia, promulgada em 1979, buscava preservar membros da corporação e por extensão a própria instituição militar de ações que procurassem pagar as dívidas com o passado. Nas palavras dos autores, isso se constituía num muro protetor à autonomia militar (p.356-60). A conclusão a que se chega é de que a anistia de 1979 surgiu de um desdobramento do controle militar sobre o processo de transição e consistiu, segundo os autores, numa medida juridicamente incongruente, eis que a prática de torturas, mortes e desaparecimentos forçados jamais poderia ser considerada conexa à prática de um delito (p.358).

A jornalista Glenda Mezarobba, noutro texto, intitulado "Anistia de 1979: o que restou da lei forjada pelo arbítrio?", constata a expansão das fronteiras legais originais em torno da anistia e indica as mudanças de significado político de um processo que ainda se encontra em desenvolvimento. Destaca que, ao longo desse processo, o Estado investiu sobretudo em uma "justiça administrativa", voltada para a reparação mediante o pagamento de indenizações (p.378). Naquele primeiro momento, em 1979, pode-se dizer que a anistia significou uma tentativa de restabelecimento das relações entre militares e opositores do regime que haviam sido cassados, banidos, estavam presos ou exilados. A legislação continha a ideia de apaziguamento, de harmonização de divergências e, ao permitir a superação de um impasse, acabou por adquirir um significado de concilia- ção pragmática, capaz de contribuir com a transição para o regime democrático (p.375). No artigo "A anistia brasileira em comparação com as da América Latina: uma análise na perspectiva do direito internacional", de Lucia Elena Arantes Ferreira Bastos, a análise sobre a anistia fundamenta-se a partir da posição do direito internacional a respeito do tema, valendo-se dos relatórios e jurisprudência do sistema interamericano de direitos humanos que integra a Organização dos Estados Americanos, dos tratados multilaterais que versam sobre direitos humanos e das resoluções e recomendações da Organização das Nações Unidas (p.345-6). O capítulo "Anistia anamnese vs. Anistia amnésia: a dimensão trágica da luta pela anistia", de autoria de Heloisa Amelia Greco, procura mapear os diferentes movimentos de luta pela anistia, a partir da perspectiva dos militantes das entidades de anistia como os Comitês Brasileiros de Anistia e o Movimento Feminino pela Anistia (p.525). Em "Anistia e (in)justiça no Brasil: o dever da justiça e a impunidade", o crítico literário Márcio Seligmann-Silva analisa a diferença entre, de um lado, o conceito inicial implícito nas reivindicações da oposição pela anistia e, de outro, a anistia de fato estabelecida em 1979. Argumenta que essa anistia implicou até hoje a impunidade dos crimes praticados pelo terrorismo de Estado (p.551-3).

Noutro conjunto temático, sobressai a discussão sobre a atual situação em que se encontram os arquivos da ditadura e os problemas referentes ao acesso a eles. Marlon Alberto Weichert, procurador de República, a partir dessa perspectiva, aborda a questão do sigilo de documentos e informações produzidos pelo militares durante a ditadura no artigo 
"Arquivos secretos e direito à verdade" (p.409). No texto aponta inconstitucionalidades e incoerências que comprometem, ainda hoje, o exercício dos direitos fundamentais do cidadão brasileiro. Da mesma forma, a historiadora Ana Maria de Almeida Camargo, no capítulo intitulado "Os arquivos e o acesso à verdade", retoma a análise da relação entre arquivos e direito à verdade a partir da teoria arquivística (p.412-20). A autora procura desfazer uma série de equívocos encontrados na bibliografia corrente, demarcando as condições sob as quais os documentos de arquivo ganham efeito probatório. No último capítulo desse temário, "Do segredo à verdade... processos sociais e políticos na abertura dos arquivos da repressão no Brasil e na Argentina", da antropóloga Ludmila da Silva Catela, a autora perfaz uma análise na qual compara, a partir de uma perspectiva antropológica, as disputas pela definição do lugar político e social dos arquivos da repressão no Brasil e na Argentina. Segundo ela, “o arquivo é uma construção institucional derivada das disputas e lutas de memória travadas entre os agentes que intervieram em suas lógicas classificatórias” (p.356).

O último bloco temático desse segundo volume encerra com quatro contribuições que levantam a discussão sobre a constituição da memória em torno do período autoritário, durante a ditadura militar. O crítico literário Jaime Ginzburg, por exemplo, em "A ditadura militar e a literatura brasileira: tragicidade, sinistro e impasse", examina o modo como a literatura brasileira pode oferecer elementos para se repensar a memória da ditadura. Tal como Seligmann-Silva, em capítulo mencionado anteriormente, Ginzburg encontra nas artes tentativas de suprir a necessidade do trabalho da memória que não tem sido feito na esfera política e jurídica, sobretudo a partir da análise do conto "Os sobreviventes", de Caio Fernando Abreu, e a crônica intitulada "Lixo", de Luís Fernando Veríssimo (p.558). Também o problema da memória e dos mitos fundadores da resistência político-cultural no regime militar é tema no capítulo "História, memória e verdade: em busca do universo dos homens", da historiadora Denise Rollemberg. De um modo amplo, discute as abordagens da historiografia sobre as relações entre sociedade e regimes autoritários. Segundo a autora, os historiadores têm centrado suas análises no Estado e na resistência, com interpretações distorcidas ou parciais sobre a participação da sociedade nos processos autoritários. Rollemberg propõe que os regimes sejam concebidos como um "produto social" (p.570). O capítulo de autoria do organizador da coletânea, Edson Teles, intitulado "Políticas do silêncio e interditos da memória na transição do consenso", também considerando a construção da memória da repressão, apresenta uma crítica da transição política brasileira, pensada com base nos atos de memória e das ações políticas relacionadas à violência política vivida durante a ditadura militar (p.580). No Brasil, segundo o autor, não houve nenhuma iniciativa do Estado de punir os criminosos da repressão política. "Sob o manto silencioso de uma reconciliação extorquida, a transição não atendeu à demanda por mudanças políticas" (p.350). Numa perspectiva que aborda o papel da mobilização jurídica transnacional dos direitos humanos na construção da memória da ditadura militar no Brasil, a socióloga Cecília MacDowell Santos, em "A justiça ao serviço da memória: mo- 


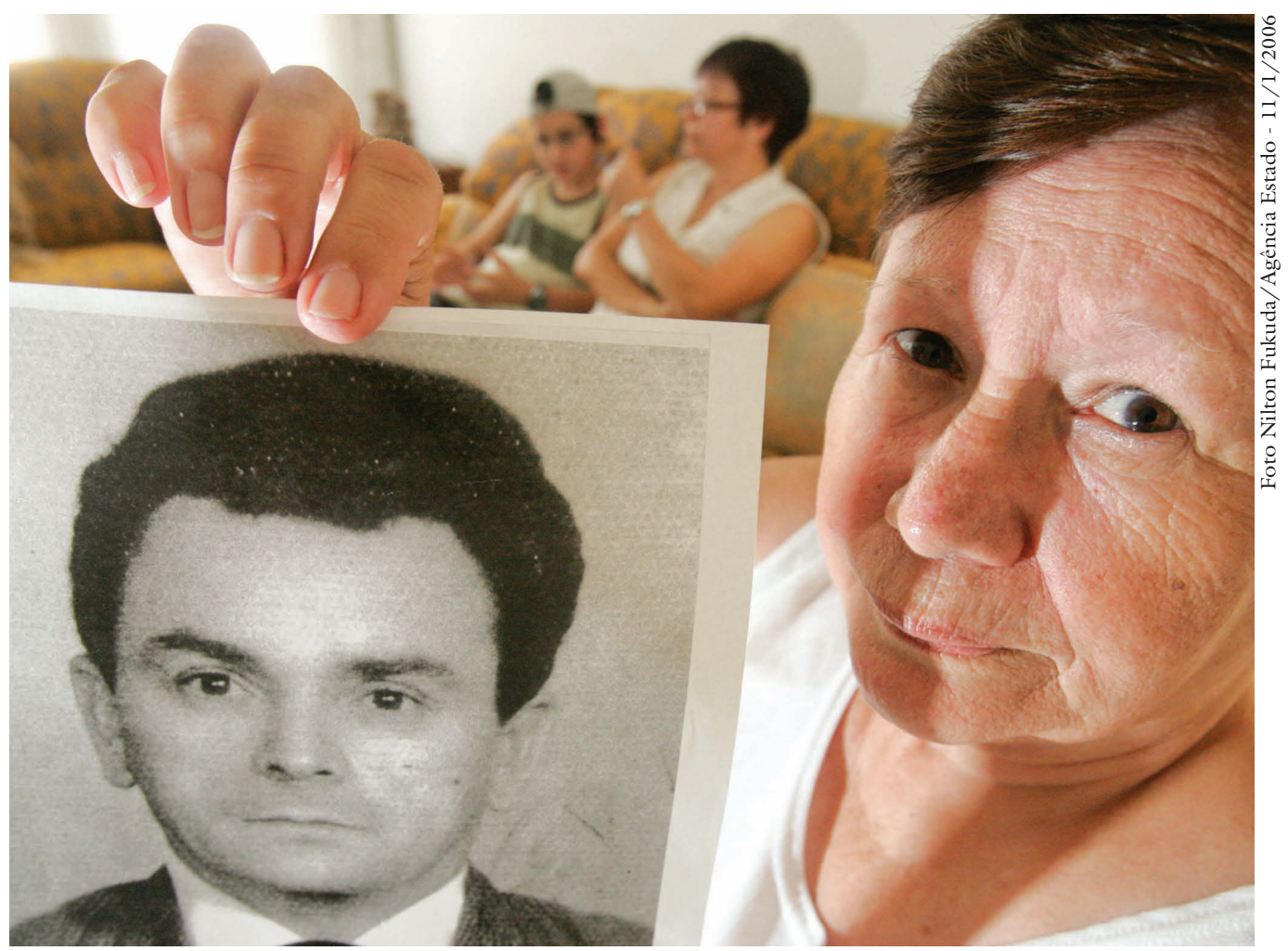

A viúva Thereza de Lourdes Martins Fiel exibe a foto de Manoel Fiel Filho, operário morto no período da ditadura militar nos porões do DOI-COI.

bilização jurídica transnacional, direitos humanos e memória da ditadura", analisa a construção dessa memória com base em denúncias de violações dos direitos humanos, cometidas pelo Estado durante a ditadura e que foram encaminhadas à Comissão Interamericana de Direitos Humanos a partir de 1969 (p.473).

E por fim, a historiadora Zilda Márcia Gricoli Iokoi, em capítulo intitulado "A longa tradição de conciliação ou estigma da cordialidade: democracia descontínua e de baixa intensidade", analisa o conceito de "transição", tal como formulado por intelectuais e pelo poderes dominantes ao longo de transformações políticas no Brasil, desde a Monarquia até a contemporaneidade (p.499-503). Para a autora, a transição "pelo alto", na versão construída tanto pelas forças repressivas como pela intelligentsia das classes dominantes, serve para arrefecer e encobrir as demandas de sujeitos sociais oprimidos (p.504-9).

Numa perspectiva abrangente e multifacetada, a coletânea contempla inúmeros enfoques sobre um tema caro à sociedade brasileira: a ditadura militar e a (in)existência de reparos às vítimas da repressão. Mais que isso: as colaborações definem e ampliam a discussão em torno da invenção de uma memória em torno das resistências das esquerdas políticas e da fabricação de discursos coesos e legitimadores a partir dos aparelhos repressivos do Estado. Não há perspectiva que sobreponha as demais, logo, o extenso trabalho dá voz às inúmeras intervenções oriundas tanto da academia quanto do espaço público e convergem para esse 
objetivo comum que é de percorrer os labirintos da memória e identificar sua matéria a partir dos objetos tomados para análise nessa coletânea.

Miliandre Garcia é pós-doutoranda em História pela Universidade de São Paulo (USP) e professora adjunta da Universidade Federal dos Vales do Jequitinhonha e Mucuri (UFVJM), em Diamantina/MG. $@$ - milidesouza@yahoo.com.br 